\title{
Global Electric Circuit research at Graciosa Island (ENA-ARM facility): First year of measurements and ENSO influences
}

\author{
Francis M. Lopes a , Hugo G. Silva ${ }^{\mathrm{a},{ }^{*}, \text { Alec J. Bennett }}{ }^{\mathrm{b}}$, A. Heitor Reis ${ }^{\mathrm{c}}$ \\ ${ }^{a}$ Renewable Energies Chair, University of Évora, IIFA, Palácio do Vimioso, Largo Marquês de Marialva, 7002-554, Évora, Portugal \\ ${ }^{\mathrm{b}}$ Bristol Industrial and Research Associates Limited (Biral) \& Department of Electronic and Electrical Engineering, University of Bath, UK \\ c Department of Physics, ICT, Institute of Earth Sciences, University of Évora, Rua Romão Ramalho 59, 7002-554, Évora, Portugal
}

\section{A R T I C L E I N F O}

\section{Article history:}

Received 25 October 2016

Received in revised form 4 May 2017

Accepted 4 May 2017

\section{Keywords:}

Global Electrical Circuit

Atmospheric electrical field

Marine aerosols and ions

El Niño-Southern Oscillation (ENSO)

\begin{abstract}
A B S T R A C T
Around 100 years after Carnegie expeditions discovered the Global Electric Circuit, a measuring campaign started at ARM, Eastern North Atlantic facility (Graciosa Island, Azores), meant for the first time to resemble the conditions in which those took place. Here, the first year of measurements (starting April 2015) are analysed and initial results are discussed. The Potential Gradient findings show a deviation from the Carnegie Curves towards inland measurements as a consequence of local aerosol and ion load. The Potential Gradient maxima evolves from 18 UTC (spring/autumn) to 20 UTC (summer), being consistent with the strong 2015 El Niño.
\end{abstract}

๑) 2017 Published by Elsevier B.V.

\section{Introduction}

Evidence of an existing Global Electrical Circuit (GEC) affecting the Earth's electric environment was first observed and recorded by the Carnegie cruise expedition (1909-1929), with the globallysynchronized diurnal variation of the Atmospheric Electric Potential Gradient ${ }^{1}$ (PG) becoming known as the Carnegie Curve [1]. This general curve, which is defined as the average daily evolution of the PG measured at different locations in the Pacific and Atlantic Oceans, results from measurements that were remarkably similar. The observations performed show that the curve is characterized by having a minimum around 3 UTC $(\sim 111 \mathrm{~V} / \mathrm{m})$ and a maximum around 20 UTC $(\sim 156 \mathrm{~V} / \mathrm{m})$. Since early publications, e.g. [2], the Carnegie Curve became central to Atmospheric Electricity, being frequently used as a state of reference. This practice results from the close relation between the daily variation of the Carnegie Curve and the global thunderstorm activity, as initially observed by Ref. [3]. Such relation was interpreted as the first evidence of an existing GEC, supporting previous studies [4]. In a simplistic description, it is

\footnotetext{
* Corresponding author.

E-mail address: hgsilva@uevora.pt (H.G. Silva).

1 The PG is related to the vertical component of the atmospheric electrical field, $E_{z}$, by the formula $P G=-E_{z}$. To guarantee positive values for the $P G$ in fair-weather conditions.
}

believed that thunderstorm activity charges the Ionosphere (in disturbed regions), which is discharged by an electric current (from the Ionosphere to the Earth's surface) through the weakly electrically conductive atmosphere (in fair-weather regions), forming the GEC. Near to the Earth's surface this electric current generates a vertical electric field that is often refereed as the potential gradient (PG). Thus, if local influences are avoided (as it was the case on the Carnegie cruise expeditions) PG curves in different locations would tend to have a similar behaviour as ruled by the GEC. The GEC is sensitive to global thunderstorm activity, which makes it a proxy for such activity.

As a consequence of the aforementioned points, since its discovery several works have been dedicated to the study of the GEC; mainly to its relation with Earth's climate [1]. As a matter of fact, in recent years a renewed interest in GEC appeared as a consequence of finding a link between the variation of lighting distribution and the El Niño-Southern Oscillation (ENSO) [5]. Moreover, it was observed [6] that a close correlation between the ENSO and lighting activity was apparent during each individual season of the year (from 1996 to 2013). An increase in lightning in the Eastern Pacific near the Americas coast (June, July and August) was found, being more significant near the equator (September, October and November). If the ENSO affects lightning it also affects GEC; in fact, another study considering measurements carried out in Scotland [7] showed a response of atmospheric electricity to ENSO. Results 
demonstrated that the mean GEC was characterized by an increase and a decrease during the "El Niño" and "La Niña" phases, respectively [7]. Due to all this interest, significant efforts are being made in GEC research in order to find suitable locations to capture global signals from the GEC while overcoming signals from local electrical activity. Such studies include: Indian Ocean [8], Antarctica [9,10], Himalayas [11], Southern America [12] and Negev desert [13]. Contributions have also been given to the understanding of the GEC variability, e.g. [14,15], including the development of numerical models, e.g. [16-18] and aircraft measurements [19]. Such models require measurements of the atmospheric electric field in well instrumented locations to nourish the modelling as much as possible with parameters that characterize the atmospheric and boundary layer systems (e.g., aerosol load, wind vector, air temperature, air relative humidity, atmospheric pressure, nebulosity).

As part of the GEC research effort, the present authors initiated a five-year PG measurement field campaign at the ARM Eastern North Atlantic (ENA-ARM) Facility [20]. This is the first time that a campaign is realized in conditions which are meant to resemble the ones of the Carnegie cruise expeditions, but allowing for longer and continuous measurements to be made. ENA-ARM is located at Graciosa Island of the Azores Archipelago and constitutes a strategic observatory for Atmospheric Electricity. Since the ENA's facility is located in the Atlantic Ocean basin, atmospheric measurements will be exposed to clean marine conditions and thereby will have a reduction in the well-known signature of anthropogenic pollution, [21]. In fact, clean areas, in which natural and anthropogenic aerosols are substantially reduced, are excellent for the study of the GEC, since PG measurements are not affected by such air particles, allowing the measurements to show the signature of the GEC itself. This should be the case of an island, as it is for Graciosa, in which the influence of continental aerosols is almost negligible. This research project stands as an initial contribution to the understanding of the evolution of the GEC regarding the network effort on putting together different measuring sites in Europe (COST Action 15211, Atmospheric Electricity Network: coupling with the Earth System, climate and biological systems).

The present work describes in detail the campaign by addressing the first year of PG measurements (starting on April 2015) and presents its initial results with several insights into local and global influences. The remainder of this paper is structured as follows: Section 2 describes in detail the measurement campaign. Results and discussions are given in Section 3, while conclusions and future work perspectives are presented in Section 4.

\section{Description of the campaign}

The Graciosa Island of the Azores Archipelago is located at $39^{\circ} 5^{\prime}$ $29.68^{\prime \prime} \mathrm{N}, 28^{\circ} 1^{\prime} 32.34^{\prime \prime} \mathrm{W}$ (Fig. 1) and is situated in the northwest tectonic structure known as the Terceira Rift, which contributed to the shape of the island ( $12.5 \mathrm{~km}$ long by $8.5 \mathrm{~km}$ in wide). The island comprises several active volcanic features including a wellpreserved volcano with a caldera (with a diameter up to $1.6 \mathrm{~km}$ and a depth of $270 \mathrm{~m}$ ) in the southeast tip of the island that resulted from a collapse. Other structures in the island have been shaped by the local tectonics such as cliffs, escarpments and reliefs punctuated by several volcanic cones. The island geomorphology results predominantly from low explosivity volcanism which started approximately 6 hundred thousand years ago due to the faults that transverse the area. During the formation of the Graciosa Island, sheets of pumice were layered, along with sub-aerial deposits which resulted from the low explosive basaltic eruptions. Further details concerning the island geomorphological evolution can be found in literature [22].

The ARM Eastern North Atlantic (ENA-ARM) facility is located in the Atlantic Ocean basin (marked as a red dot depicted in the globe of Fig. 1). The ENA facility measures a wide range of different meteorological parameters (Table 1) that play a crucial role in atmospheric modelling and could be of interest to GEC research. The field-mill used for the local PG measurements is a JCI 131F and is installed at $2 \mathrm{~m}$ height above ground ( $31 \mathrm{~m}$ from sea level) and at a horizontal distance of $500 \mathrm{~m}$ from the seashore. As commonly performed in PG measurements [23], the field-mill used is a JCI $131 \mathrm{~F}$ (Chilworth, UK), being calibrated in December 2013. The device was installed at $2 \mathrm{~m}$ height above ground $(\sim 31 \mathrm{~m}$ from sea level) and at a horizontal distance of $500 \mathrm{~m}$ from the seashore. This device was developed by Dr. John Chubb and recent work revealed a flat spectral response up to frequencies of $\sim 100 \mathrm{~Hz}$ [24]. A rate of one second sampling was used, with 1-min mean and standard deviation being performed. A SOLYS2 Sun Tracker (from Kipp \& Zonen) is installed near the PG sensor to perform a complete solar monitoring, allowing the recording of the three components of the local solar irradiance (i.e., direct normal, diffuse and global horizontal irradiances). Additionally, the Aerosol Robotic Network (AERONET, https://aeronet.gsfc.nasa.gov) station, also located at Graciosa Island, is used to perform spectral aerosol optical depth (AOD) measurements, which measures the level of solar radiation extinction due to aerosol load present in the atmospheric column. The instrument used to measure AOD is a multiband spectrophotometer CIMEL CE-318-2. In the following, only the $440 \mathrm{~nm}$ wavelength is analysed due to its sensibility to particles with volume radius lower than $0.5 \mu \mathrm{m}$ (aerosol fine mode). Additionally, other atmospheric and boundary layer measurement equipment are also available nearby the installation site (see Table 1 ).

\section{Results and discussion}

An initial assessment of the first year of measurements, starting on April 1st, 2015, of the PG in the Graciosa Island is depicted in Fig. 2. It should be mentioned that results discussed in this section are unrepresentative of a long term change due to the fact that the time series only comprises one year, but are still representative of short term phenomena due to the same nature of PG measurements [12]. Even though, many studies have found consistent/ robust results in atmospheric electricity with shorter time series. The raw data of the PG (Fig. 2a) is presented and, in terms of clarity in the representation, the data is restricted to the range $[0,400] \mathrm{V} /$ $\mathrm{m}$ (only $\sim 3 \%$ of the data is neglected) and the correspondent statistical details are shown in Table 2 . A high variability characteristic of these type of measurements is observed. These oscillations can occur due to a number of local factors such as nebulosity, rain, strong winds, space charges, and even nearby insect or bird activity. This reflects the high sensibility of the measuring equipment and for that reason only data that comprises fair-weather (FW) days will be used further in the analysis. FW days are determined on the basis of the nebulosity index (further defined below). Moreover, in Fig. 2a, a lowess smoothing curve (solid blackline) is added to the plot, as well as the PG monthly average values which depict well the yearly variation of the PG. Contrary to what is observed in urban environments, i.e., a tendency for lower PG values in the summer [21], no clear annual tendency is observed in Graciosa with the lower monthly PG value being found for January $(\sim 64.4 \mathrm{~V} / \mathrm{m})$ and higher on October $(\sim 102.8 \mathrm{~V} / \mathrm{m})$. Monthly PG variability (inset in Fig. 2a) does seem to have some degree of seasonal tendency with summer months having lower standard deviation (STD). Nevertheless, lower STD values are found on February $(\sim 38.8 \mathrm{~V} / \mathrm{m})$ and higher values on September $(\sim 472.3 \mathrm{~V} / \mathrm{m})$. For the sake of clarity, seasons are separated as: spring that comprises March, April and May (MAM); summer that includes June, July and August (JJA); autumn that contains September, October and November (SON); 


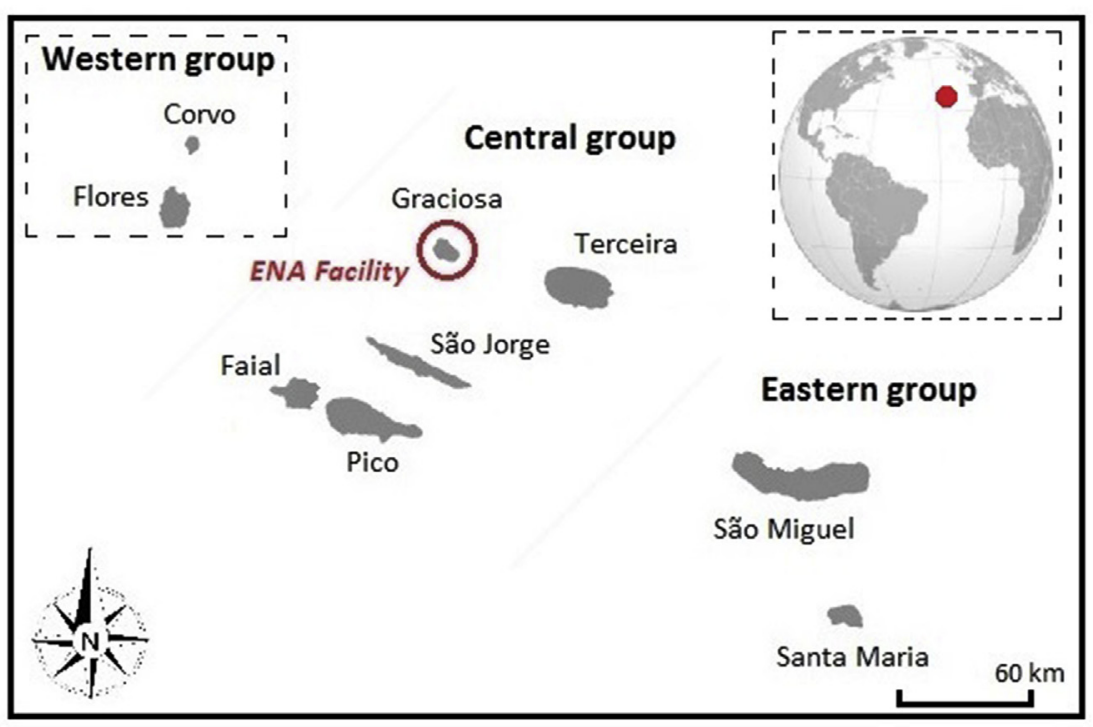

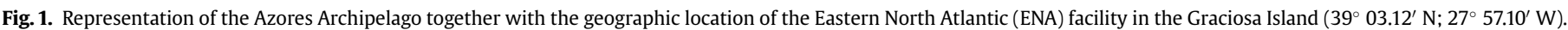

Table 1

List of available parameters measured at the ARM Eastern North Atlantic (ENA-ARM) facility in Graciosa Island (Azores). Only a few examples are shown here. More details are available at www.arm.gov/measurements.

\begin{tabular}{lll}
\hline Parameter & Category & Instrument \\
\hline Aerosol optical depth (AOD) & Aerosols & High Spectral Resolution Lidar (HSRL) \\
Atmospheric pressure & Atmospheric state & Microwave Radiometer - High Frequency (MWRHF) \\
Precipitation & Atmospheric state & Surface Meteorological Instruments (SMET) \\
Atmospheric moisture & Atmospheric state & Infra-Red Sky Imager (IRSI) \\
Aerosol particle size distribution & Aerosols & Ultra-High Sensitivity Aerosol Spectrometer (UHSAS) \\
Cloud fraction & Cloud properties & Infra-Red Sky Imager (IRSI) \\
Surface temperature & Surface properties & Surface Meteorological Instruments (SMET) \\
Planetary boundary layer height & Atmospheric state & Ceilometer (CEIL) \\
Net broadband total irradiance & Radiometric & Surface Energy Balance System (SEBS) \\
\hline
\end{tabular}

winter that involves December, January and February (DJF). These definitions will be used further on.

Generically, different hypothesis may be given to explain PG variability throughout the year at Graciosa, both from local and global nature. Among the local phenomena that might affect the PG are: (1) the atmospheric electric field which can be charged or discharged due to the reduction or increase in the air conductivity, respectively; (2) the influence of clouds, as these are charged and tend to increase the PG [25]. The first hypothesis considers the variation of the air conductivity, which can occur by four different mechanisms: (i) variation in the concentration of small marine ions brought by the sea breeze [26], since the measurements are performed close to the sea $(\sim 500 \mathrm{~m})$; (ii) the generation of spacecharges due to the burst of water droplets by wave splashing, the so called balloelectric effect [27] and references therein; (iii) variation of the local ionization by the variation of the emission rate of natural radioactive gases, mainly radon [28]; (iv) reduction or increase of the small ions concentration by an increased or reduced scavenging of the existing ions by water droplets and hygroscopic particles [29], respectively. In terms of global effects, the PG values tend to increase or decrease as a result from an addition or reduction in the charging of the GEC, respectively, by the generators, mainly lightning. Although the present results do not show a clear seasonality of GEC, the work of Tacza and co-authors [12] give support to the present findings. The authors presented a three-year analysis of PG data in South America stations, observing that the average daily shape during a month, season or year repeats similarly for different years. This is somehow contradictory with the seasonal variations observed on the Carnegie expedition data [1].

Moreover, the analysis for the diurnal variation shows that the PG can be affected by different factors throughout the day. The criteria applied for the selection of the FW days was established on the nebulosity index $\left(K_{n}\right)$ which is defined as the ratio between the diffuse $\left(E_{d}\right)$ and global $\left(E_{g}\right)$ horizontal irradiances (Fig. $2 b$ ):

$K_{n}=\frac{E_{d}}{E_{g}}$,

where the index typically goes from 1 for overcast-sky to $\sim 0.2$ in clear-sky conditions. Eq. (1) is a simplification of the Perraudeau nebulosity index [31]. The obtained 1-day $K_{n}$ is depicted in Fig. 2c. To apply the nebulosity index in the FW selection, a number of different $K_{n}$ were taken into account (Fig. 3). The results show a diverse number of FW days (Table 3 ) and the corresponding average daily PG for each $K_{n}$ obtained are shown in Fig. 3. The nebulosity index that was selected for further analysis was for $K_{n}<0.4$, as a trade-off of a statistically representative sample ( 28 days) and a smooth variation of the average daily PG curve (low relative standard deviation). PG curves for $\mathrm{K}_{n}<0.5$ and $\mathrm{K}_{\mathrm{n}}<0.6$ are not suitable for our FW criteria since they show sharp oscillations between 4 and 6 UTC that might be attributed to disturbed weather conditions. Additionally, an inset with the relative standard deviation (\%) for each PG curve corresponding to different $K_{n}$ is also 

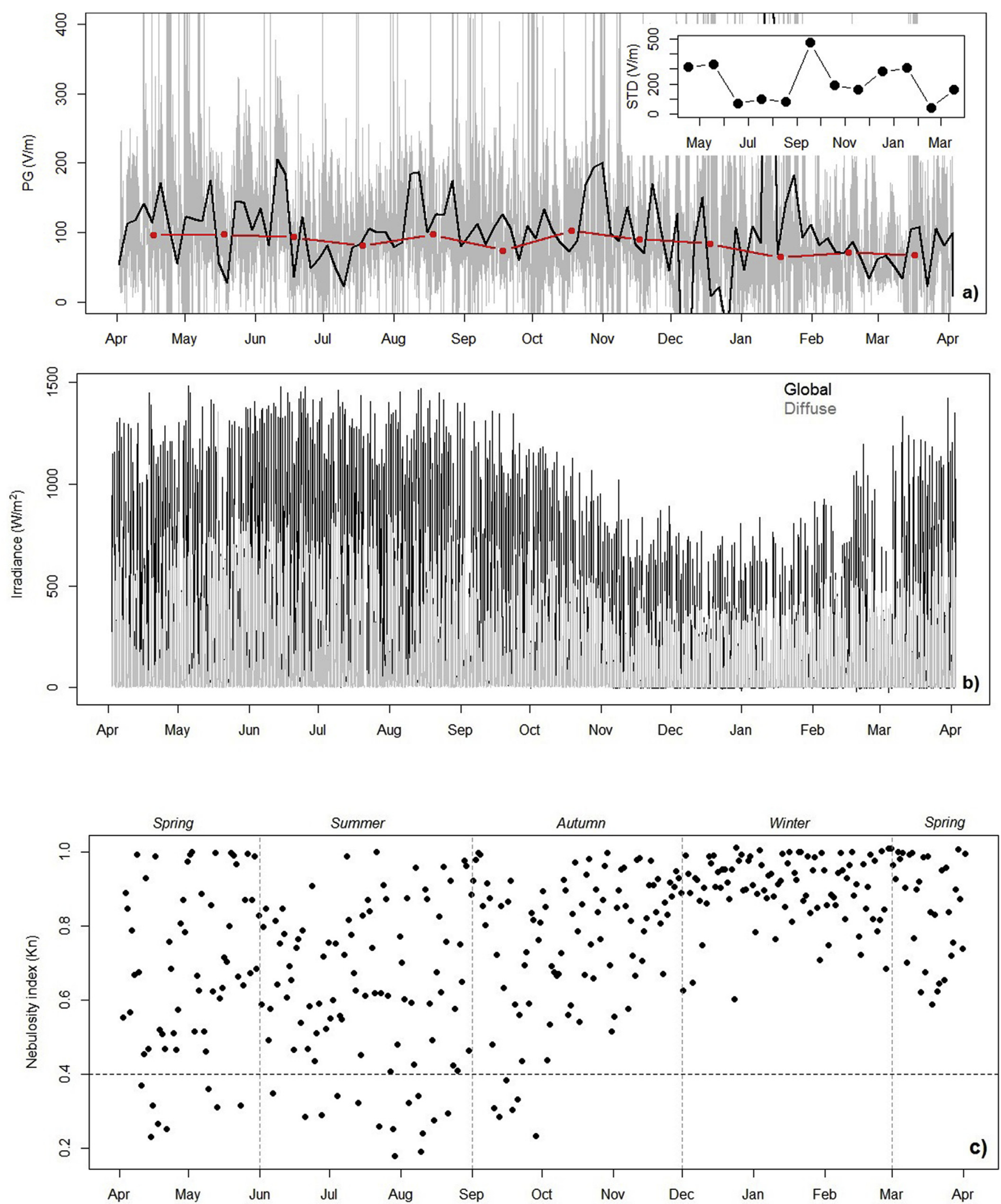

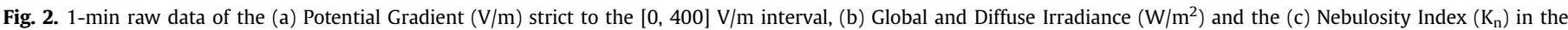

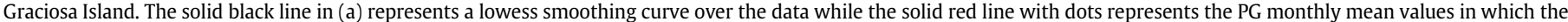

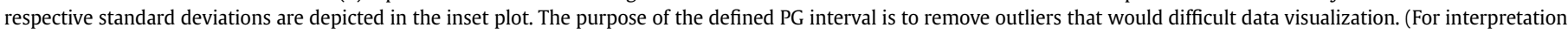
of the references to colour in this figure legend, the reader is referred to the web version of this article.) 
Table 2

Maximum, minimum, mean, median, standard deviation (STD), skewness, kurtosis, and number of days for PG raw and fair-weather (FW) data.

\begin{tabular}{lll}
\hline & Raw PG & FW PG \\
\hline Maximum $(\mathrm{V} / \mathrm{m})$ & 7000.0 & 1096.0 \\
Minimum $(\mathrm{V} / \mathrm{m})$ & -7000.0 & -816.0 \\
Mean $(\mathrm{V} / \mathrm{m})$ & 84.6 & 90.0 \\
Median $(\mathrm{V} / \mathrm{m})$ & 86.6 & 89.9 \\
STD $(\mathrm{V} / \mathrm{m})$ & 243.9 & 37.5 \\
Skewness & -6.7 & 0.36 \\
Kurtosis & 343.0 & 33.87 \\
Number of days & 366 & 28 \\
\hline
\end{tabular}

depicted in Fig. 3, as it was obtained through:

$S T D_{\text {rel }}=\frac{P G_{\text {Std }}}{\overline{P G}} \times 100(\%)$.

The small plot in Fig. 3a shows that the selected nebulosity index $\left(K_{n}<0.4\right)$ is the one that presents the best combination between a low relative standard deviation (i.e., a smooth variation from the mean value) and significant statistical samples (in this case, 28 FW days). The statistical details of FW PG are given in Table 2.

A deviation from the Carnegie Curve is observed in the FW PG daily mean curve: lower values with a more pronounced increase in the late morning hours (7-10 UTC) and a smooth variation during the afternoon. Additionally, a correlation of $\sim 0.71$, with a p-value $<$ 0.0001, was found between the selected Graciosa PG curve (marked in black) and the Carnegie Curve. The overall lower PG values, as compared with the Carnegie Curve, could be either related to instrumentation or to local effects. One of them is the ionization created by natural radioactive gases (radon) that is present in land territory, but absent in the ocean environment. It is commonly accepted that the two main sources of atmospheric ionization are cosmic rays and radon, and to this it can be added the breaking of waves near the seaside [32,33] which is the case of Graciosa Island. In fact, being a volcanic Island it can enhance radon migration from the Earth's surface [30]. These co-located measurements of radon are currently under operation and future analysis will consider both radon and PG together. In the case of measurements in the open ocean like the ones performed by the Carnegie [1] and other cruises [34], the only source of ionization is cosmic rays and for that reason lower air conductivity is observed in such conditions [34] and, as a consequence of Ohm's law, the PG values are higher. The presence of natural radioactivity is possibly one of the main differences between the conditions in which the Carnegie Curve was measured and the measurements made in Graciosa Island. Another possibility is the presence of marine ions, as the Carnegie Curve results from measurements taken aboard ships, where there were no breaking waves, contrary to Graciosa where waves break all along the coastline, allowing the generation of many marine ions. These ions are highly mobile and tend to discharge the local electric field by increasing air's conductivity. This effect has been reported by Ref. [32] which observed that when the wind direction came from the sea there was a greater influence of marine air leading to an increase of the air conductivity.

A closer look into the data, having in mind the size of the current time series, the same nebulosity index criteria was applied and divided into seasons: spring (MAM); summer (JJA); autumn (SON) and winter (DJF). This way, it was found the existence of 8 FW days for spring, 14 FW days for summer and 6 FW days for autumn and none for winter. The mean daily PG curves and corresponding Carnegie Curves (CC) (obtained from parameters estimated by Ref. [1]) for each season are shown in Fig. 4a, b and c. In these plots, it was added the mean daily AOD behaviour for the corresponding days of FW used in the PG calculations for each season. Generally, the summer tends to show lower values of AOD coinciding with a better agreement between the PG and CC curves on this season. This could be indicative of the role that aerosols, as a local effect, might have in the deviation of the measured PG from the signal imposed by the global modulation of the electric field as uttered by the CC.

Comparing the PG curves in the three seasons, it is seen that they have a similar behaviour showing the expected minima at dawn and the maxima at the evening (in conformity to the minima and maxima observed in CC for each season). The small contrasts observed are probably due to the fact that the PG measurements at Graciosa are more sensitive to thunderstorms in America, Europe

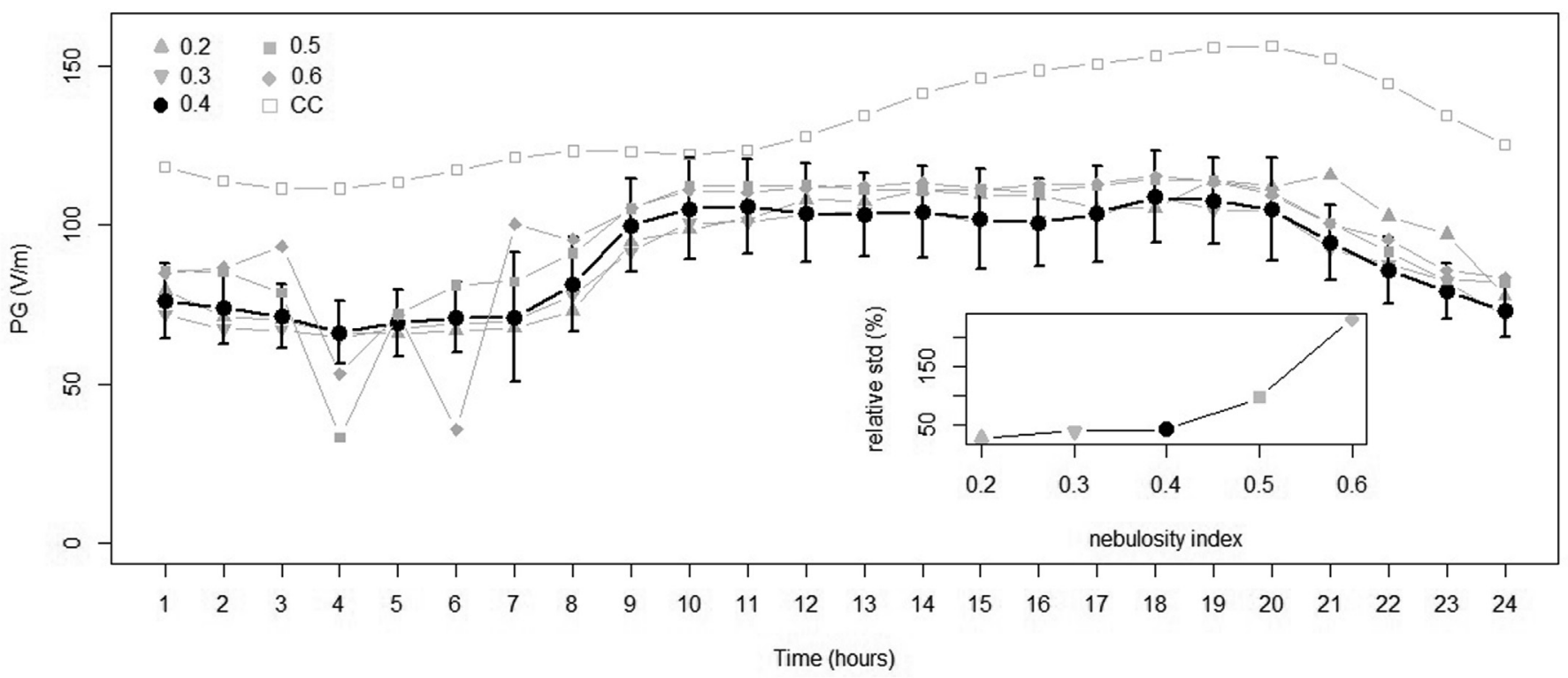

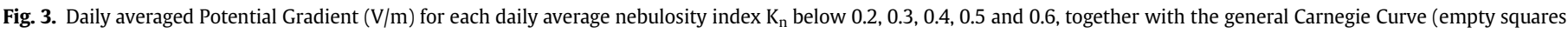
time series). Error bars are added to the PG curve corresponding to the 0.4 nebulosity index, whilst the inset shows the relative standard deviation (\%) for each PG curve. 
Table 3

The obtained number of fair-weather (FW) days for each nebulosity indices $\left(\mathrm{K}_{\mathrm{n}}\right)$ according to Eq. (1) and their respective relative standard deviation (\%) obtained through Eq. (2).

\begin{tabular}{lll}
\hline Nebulosity index $\left(\mathrm{K}_{\mathrm{n}}\right)$ & Number of FW days & Relative standard deviation $(\%)$ \\
\hline$<0.2$ & 2 & 25.5 \\
$<0.3$ & 14 & 38.9 \\
$<0.4$ & 27 & 41.6 \\
$<0.5$ & 48 & 96.7 \\
$<0.6$ & 81 & 233 \\
\hline
\end{tabular}

and Africa than in Asia and Australia. In the first three regions, thunderstorm activity tends to have its minima later in comparison with the last two ones [1]. In terms of the daily PG maxima, they occur at 18 UTC in spring (second dashed line in the plots), 19-20 UTC in the summer (dotted line in the plots), and 18-19 UTC in autumn, this is approximately one hour earlier than the CC references that have their maxima at 19-20 UTC, 21-22 UTC and 19 UTC, respectively for spring, summer and autumn. This shows that the seasonal change in the time of occurrence of the afternoon PG maximum at Graciosa is consistent with the change of the maximum of the CC references (Fig. 4a, b and c); though the CC maxima occur around one hour later. The fact that PG maxima are recorded earlier in Graciosa Island, relates also the possibility of the proximity to the European and African continents, which thunderstorm activity peaks are attained around 13 UTC; while the American thunderstorm activity peaks around 19 to 20 UTC [1].

In this context, the effect of the strong 2015 El Niño, should help understanding the seasonal change in the time of occurrence of the PG maximum at Graciosa. In Fig. 5, large positive weekly sea surface temperature (SST) anomalies in the Eastern Pacific, Niño $1+2$ $\left(0-10^{\circ}\right.$ South, $90^{\circ}-80^{\circ}$ West $)$ and Niño $3\left(5^{\circ}\right.$ North $-5^{\circ}$ South, $150^{\circ}-90^{\circ}$ West), are clearly identified for 2015 . The SST anomalies are depicted with a strong increase during the spring (dashed vertical line) and summer (pointed vertical line) months. The ENSO data from January 6th, 2010 to July 27th, 2016 here presented was retrieved from NOAA's website (www.cpc.ncep.noaa.gov). El Niño is known to affect the global distribution of thunderstorms, shifting eastwards the Pacific thunderstorms, increasing the relevance of the American thunderstorms peak in Graciosa Island. In fact, there is a growth in the intensity of thunderstorm activity between spring and summer over North America [35] which results from the ENSO strengthening that has been happening since 1996. Comparison with La Niña years will be done in the future.

On the other hand, the first vertical dashed lines mark the observed PG increase during the morning (around 9-10 UTC) for the three curves in Graciosa, but not observed in the Carnegie reference curves that show a smooth increase from the dawn minima to the evening maxima. This deviation of the diurnal Graciosa PG from the CC during the late morning is difficult to interpret in the context of the GEC. Such deviation is expected to be due to near-surface aerosol generated in the island after sunrise which would reduce the air conductivity in the morning. In some respect, this is a common feature to inland stations in which it is often observed a double maximum: (1) in the morning, due to the rise of near-surface aerosols; (2) in the evening, due to the GEC. This behaviour is particularly clear for the spring and autumn PG curves in Graciosa, Fig. 4a and c. Nevertheless, the mean AOD values for that time (9-10 UTC) of the day are low $(0.15,0.08,0.15$ for spring, summer, autumn, respectively) corresponding essentially to clean aerosol conditions according to the definition given by Ref. [36]: AOD $(440 \mathrm{~nm})<0.12$. More interesting is the fact that in the period from 10 UTC to 16-17 UTC, while there are relatively high values of AOD, the PG seems to suffer a reduction. In fact, there seems to be an AOD peak (13 UTC in spring and 15 UTC in summer and autumn, reaching $0.65,0.15,1.65$ respectively for each season) accompanied by a PG minima one to three hours later (16 UTC in spring, 17 UTC in summer, and 16 UTC in autumn, with PG values of 107.7, 98.9, $81.4 \mathrm{~V} / \mathrm{m}$, respectively for each season). Since the AOD data has large standard deviations (not shown here), its relevance to the PG analysis should be made with particular care. Nevertheless, the one possibility that can be thought to explain these observations is that the AOD measurements are recording aerosols mixed with some sort of charge carriers (which are not accessible to AOD). That would tend to increase the atmospheric electric conductivity (reduction of PG) and balancing the aerosol effect that tends to reduce the atmospheric electric conductivity (increase of PG). Since the measurements are made in the seaside, and according to the observations made in similar sites [32,33], the influence of marine ions can be hypothesised in order to explain these observations. Several studies can be found in literature dedicated to the formation of space-charge distributions (essentially the unbalance between positive and negative small ion clusters) at seaside locations [37-39] that might support the present hypothesis. The typical marine cations are $\mathrm{H}^{+}, \mathrm{NH}_{4}^{+}, \mathrm{Na}^{+}, \mathrm{Mg}^{2+}, \mathrm{K}^{+}, \mathrm{Ca}^{2+}$ and anions are $\mathrm{NO}_{3}^{-}, \mathrm{Cl}^{-}, \mathrm{SO}_{4}^{2-}, \mathrm{HCO}_{3}^{-}[40]$. Although they should be hydrated by water molecules while remaining in the atmosphere, these ions have high electric mobilities and should, for that reason, increase the atmospheric electric conductivity and, as a consequence of Ohm's law, they should therefore reduce the PG [32]. For this to explain the reduction of the PG while observing a peak in the AOD means that the concentration of marine ions has to be significant. A simple estimation of the amount of space-charge needed for the observed PG minimum can be made for the autumn using the Carnegie value as reference $(141.9 \mathrm{~V} / \mathrm{m})$ and the measured PG $(81.4 \mathrm{~V} / \mathrm{m})$ at $16 \mathrm{UTC}$. The difference of the two values is $\sim 60.5 \mathrm{~V} / \mathrm{m}$ and, if attributed to the space-charges created by the marine ions, it allows the use of Equation (8) from Ref. [41] (assuming similar parameters) to estimate the space-charge to be nearly $\sim 103 \mathrm{pC} / \mathrm{m}^{3}$; which is a very reasonable value $[41,42]$. Taking into account that waves break all along the seashore in the island (with a power around $\sim 20-30 \mathrm{~kW} / \mathrm{km}$ of wave front) it is easy to understand that those marine ions are constantly being sprayed to the atmosphere. The concentrations can be higher in more convective situations as it is the case for the midday. The same happens for marine aerosols, explaining the midday AOD peak. Even though, the effect of the marine ions on the PG should be prolonged since these ions have large characteristic times of recombination (well above the $\sim 20 \mathrm{~s}$ for polluted regions) as this is a very low pollution environment. After 19 UTC, the AOD is again below or near to the 0.12 threshold for clean aerosol conditions and the GEC signal is recovered as it is revealed by the evening maxima in the PG curves for the three seasons (Fig. 4a, b and c), as previously discussed.

Unlike the Carnegie cruise expeditions, which were entirely ocean-based, Graciosa is an island so it will experience wave-break and wind-blown aerosols and ions in the immediate vicinity of the electric field mill ( $500 \mathrm{~m}$ from the shore). This means that the local effects of increased aerosol and ion concentrations after sunrise until sunset are still observed, causing the PG to depart from the GEC signal and approaching it to an inland situation. Still, before sunrise and after sunset, the PG at Graciosa tends to reproduce the CC behaviour very well, making this period suitable for GEC research.

\section{Conclusions and future work}

For the first time, measurements of the atmospheric electric field have been carried out at the ARM-ENA facility in the Graciosa Island (Azores archipelago) as part of a network effort for the study 

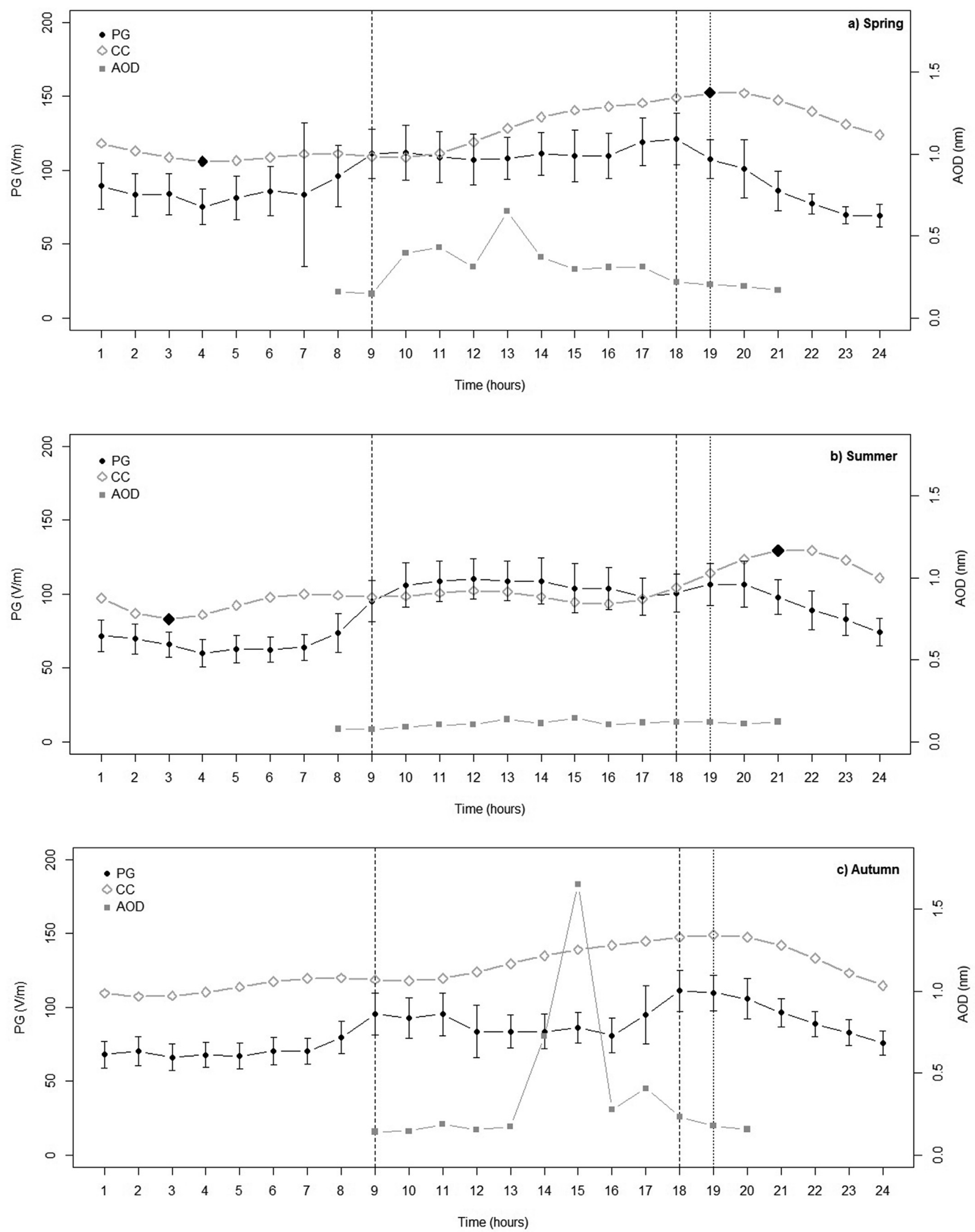

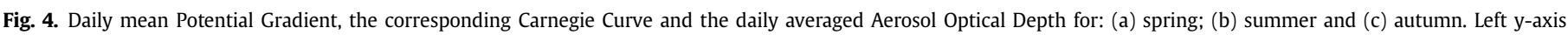
corresponds to the PG and the right y-axis to the AOD (440 nm). 


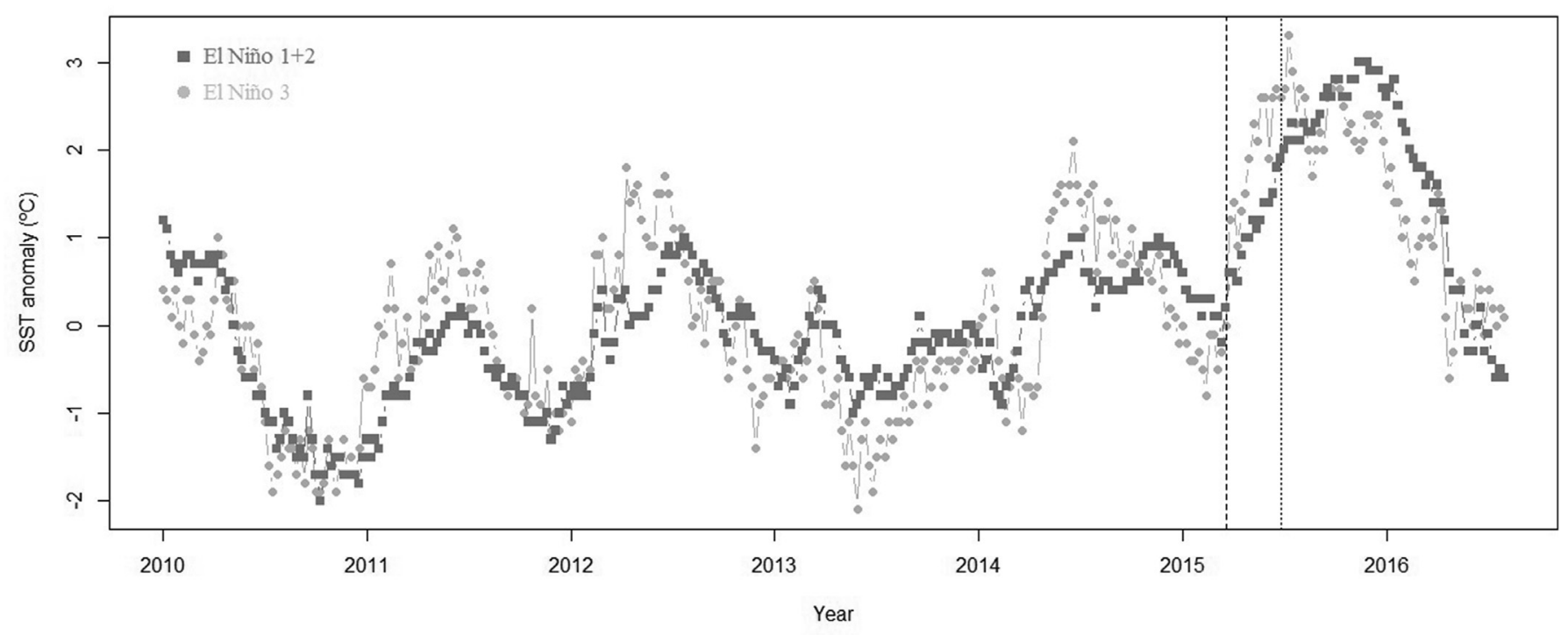

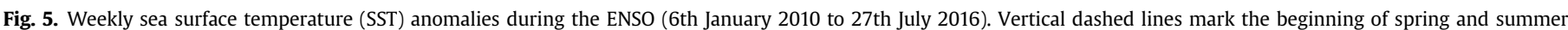

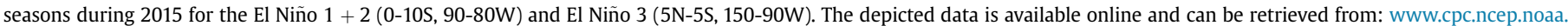
gov/data/indices/wksst8110.for.

of the Global Electrical Circuit variability. Results show that under fair-weather conditions, the island's Potential Gradient is locally affected by marine air which tends to alter the diurnal Potential Gradient away from the Carnegie towards that of what is seen at land sites. On a global scale, the Graciosa Island appears to be a good place for the study of the GEC as signatures of large scale systems such as the ENSO that is apparently observed in the seasonal changes of Potential Gradient. In short, the Potential Gradient in Graciosa Island tends to be in an intermediate situation between an inland station and a cruise station, showing similarities and discrepancies between the two cases. Between sunrise and sunset, it approaches inland stations whilst in the remainder it approaches the cruise stations.

\section{Acknowledgements}

This work was co-funded by the European Union through the European Regional Development Fund, framed in COMPETE 2020 (Operational Programme Competitiveness and Internationalisation) through the ICT project (UID/GEO/04683/2013) with reference POCI-01-0145-FEDER-007690. FML and HGS are grateful to the Renewable Energy Chair (University of Évora) for supporting this work. The authors are also deeply grateful to Dr. John Chubb for making this research possible by developing the field-mill here used. Installation and maintenance of the measuring equipment used at Graciosa Island was performed by Samuel Bárias, Carlos Sousa, Bruno Cunha and Tércio Silva, their work is here truly recognized. Finally, the authors thank Eduardo Brito Azevedo, for is support in making this research possible, and Giles Harrison for is valuable discussions and insights to the project.

\section{References}

[1] R.G. Harrison, The Carnegie curve, Surv. Geophys. 34 (2013) 209-232.

[2] L.A. Bauer, W.J. Peters, J.A. Fleming, J.P. Ault, W.F.G. Swann, Ocean magnetic observations 1905-1916 and reports on special researches, vol 3. Researches of the department of terrestrial magnetism, Carnegie Inst. Wash. Publ. 175 (1917) 378-392.

[3] F.J.W. Whipple, On the association of the diurnal variation of the electric potential gradient in fine weather with the distribution of thunderstorms over the globe, Q. J. R. Meteorol. Soc. 55 (1929) 351-361.

[4] C.T.R. Wilson, Investigations on lightning discharges and the electric field of thunderstorms, Philos. Trans. A 221 (1921) 73-115.

[5] G. Sátori, B. Zieger, El Niño related meridional oscillation of global lightning activity, Geophys. Res. Lett. 26 (1999) 1365-1368, http://dx.doi.org/10.1029/ 1999GL900264.

[6] J.D. Andrew, Seasonal forecasting of lightning and thunderstorm activity in tropical and temperate regions of the world, Nat. Sci. Rep. 6 (2016) 20874 http://dx.doi.org/10.1038/srep20874.

[7] R.G. Harrison, M. Joshi, K. Pascoe, Inferring convective responses to El Niño with atmospheric electricity measurements in Shetland, Environ. Res. Lett. 6 (2011) 044028, http://dx.doi.org/10.1088/1748-9326/6/4/044028.

[8] A.K. Kamra, C.G. Deshpande, V. Gopalakrishnam, Challenge to the assumption of the unitary diurnal variation of the atmospheric electric field based on observations in the Indian Ocean, Bay of Bengal and Arabian Sea, J. Geophys. Res. 99 (1994) 21043-21050.

[9] C.G. Deshpande, A.K. Kamra, Diurnal variations of the atmospheric electric field and conductivity at Maitri, Antarctica, J. Geophys. Res. 106 (D13) (2001) 14207-14218.

[10] G.B. Burns, A.V. Frank-Kamenetsky, O.A. Troshichev, E.A. Bering, B.D. Reddell Interannual consistency of bi-monthly differences in diurnal variations of the ground-level vertical electric field, J. Geophys. Res. 110 (2005) D10106, http:// dx.doi.org/10.1029/2004JD005469.

[11] B. Xu, D. Zou, B.Y. Chen, J.Y. Zhang, G.W. Xu, Periodic variations of atmospheric electric field on fair weather conditions at YBJ, Tibet, J. Atmos. SolarTerrestrial Phys. 97 (2013) 85

[12] J. Tacza, J.P. Raulin, E. Macotela, E. Norabuena, G. Fernandez, E. Correia, M.J. Rycroft, R.G. Harrison, A new South American network to study the atmospheric electric field and its variations related to geophysical phenomena J. Atmos. Sol-Terr. Phys. 120 (2014) 70-79.

[13] Y. Yaniv, Y. Yair, C. Price, S. Katz, Local and global impacts on the fair-weather electric field in Israel, Atmos. Res. 172-173 (2016) 119-125.

[14] M.J. Rycroft, K.A. Nicoll, K.L. Aplin, R.G. Harrison, Recent advances in global electric circuit coupling between the space environment and the troposphere J. Atmos. Solar-Terrestrial Phys. 90-91 (2012) 198-211.

[15] E. Williams, E. Mareev, Recent progress on the global electrical circuit, Atmos. Res. 135-136 (2014) 208-227.

[16] A. Odzimek, M. Lester, M. Kubici, EGATEC: a new high-resolution engineering model of the global atmospheric electric circuit - currents in the lower ionosphere, J. Geophys. Res. 115 (2010) D18207.

[17] A.J.G. Baumgaertner, J.P. Thayer, R.R. Neely III, G. Lucas, Toward a comprehensive global electric circuit model: atmospheric conductivity and its variability in CESM1 (WACCM) model simulations, J. Geophys. Res. 118 (2013) 9221-9232.

[18] R. Conceição, H.G. Silva, Simulations of the global electrical circuit coupled to local potential gradient measurements, J. Phys. Conf. Ser. 646 (2015) 012017.

[19] R. Markson, Ionospheric potential variations obtained from aircraft measurements of potential gradient, J. Geophys. Res. 81 (12) (1976) 1980-1990.

[20] H.G. Silva, A.H. Reis, ENA-ARM Campaign: Atmospheric Electric Field-mill Sensor, 2014. www.arm.gov/campaigns/ena2014aefms.

[21] H.G. Silva, R. Conceição, M. Melgão, K. Nicoll, P.B. Mendes, M. Tlemçani A.H. Reis, R.G. Harrison, Atmospheric electric field measurements in urban environment and the pollutant aerosol weekly dependence, Environ. Res. Lett. 9 (2014) 114025. 
[22] C.A. Sommer, E.F. Lima, L.M.M. Rossetti, B.L. Waichel, A. Machado, F.C. Lopes D.L. Saldanha, M.T.A. Barata, C.J. Barreto, Geochemical characteristics of volcanic rocks from Graciosa Island, Azores, Portugal: preliminary considerations, Comun. Geol. 101 (2014) 217-220.

[23] J. Chubb, The measurement of atmospheric electric fields using pole mounted electrostatic fieldmeters, J. Electrost. 72 (2014) 295-300.

[24] J. Chubb, Comparison of atmospheric electric field measurements by a pole mounted fieldmeter and by a horizontal wire antenna, J. Electrost. 73 (2015) $1-5$.

[25] K.A. Nicoll, R.G. Harrison, Experimental determination of layer cloud edge charging from cosmic ray ionisation, Geophys. Res. Lett. 37 (2010) L13802.

[26] H.G. Silva, J.C. Matthews, R. Conceição, M.D. Wright, S.N. Pereira, A.H. Reis, D.E. Shallcross, Modulation of urban atmospheric electric field measurements with the wind direction in Lisbon (Portugal), J. Phys. Conf. Ser. 646 (2015) 012013.

[27] H. Tammet, U. Hõrrak, M. Kulmala, Negatively charged nanoparticles produced by splashing of water, Atmos. Chem. Phys. 9 (2009) 357-367.

[28] F. Lopes, H.G. Silva, S. Bárias, S.M. Barbosa, Preliminary results on soil-emitted gamma radiation and its relation with the local atmospheric electric field at Amieira (Portugal), J. Phys. Conf. Ser. 646 (2015) 012015.

[29] H.G. Silva, R. Conceição, M.D. Wright, J.C. Matthews, S.N. Pereira, D.E. Shallcros, Aerosol hygroscopic growth and the dependence of atmospheric electric field measurements with relative humidity, J. Aerosol. Sci. 85 (2015) 42-51.

[30] S.M. Barbosa, P. Miranda, E.B. Azevedo, Short-term variability of gamma radiation at the arm Eastern North atlantic facility (Azores), J. Environ. Radioact. 172 (2017) 218-231.

[31] M. Perraudeau, P. Chauvel, One Year's Measurements of Luminous Climate in Nantes, Proc. Int. Daylighting Conf., Long Beach, USA, 1986.
[32] R.J. Wilding, R.G. Harrison, Aerosol modulation of small ion growth in coastal air, Atmos. Environ. 39 (2005) 5876-5883.

[33] R. Reiter, Charges on particles of different size from bubbles of Mediterranean Sea surf and from waterfalls, J. Geophys. Res. 99 (D5) (1994) 10807-10812.

[34] A.K. Kamra, C.G. Deshpande, V. Gopalakrishnam, Effect of relative humidity on the electrical conductivity of marine air, Q. J. R. Meteorol. Soc. 123 (1997) 1295-1305.

[35] H.J. Christian, R.J. Blakeslee, D.J. Boccippio, W.L. Boeck, D.E. Buechler, K.T. Driscoll, S.J. Goodman, J.M. Hall, W.J. Koshak, D.M. Mach, M.F. Stewart, Global frequency and distribution of lightning as observed from space by the optical transient detector, J. Geophys. Res. 108 (D1) (2003) 4005, http:// dx.doi.org/10.1029/2002JD002347.

[36] T. Elias, A.M. Silva, N. Belo, S. Pereira, P. Formenti, G. Helas, F. Wagner, Aerosol extinction in a remote continental region of the Iberian Peninsula during summer, J. Geophys. Res. 111 (D14204) (2006) 1-20.

[37] D.C. Blanchard, Positive space charge from the sea, J. Atmos. Sci. 23 (1966) $507-515$.

[38] S.G. Gathman, W.A. Hoppel, Surf electrification, J. Geophys. Res. 75 (24) (1970) 4525-4529.

[39] M.S. Muir, Atmospheric electric space charge generated by the surf, J. Atmos. Terr. Phys. 39 (1977) 1341-1346.

[40] R. Lonso, G. Bergametti, P. Carlier, G. Mouvier, Major ions in marine rainwater with attention to sources of alkaline and acidic species, Atmos. Environ. 25A (3/4) (1991) 763-770.

[41] F. Lopes, H.G. Silva, R. Salgado, M. Potes, K.A. Nicoll, R.G. Harrison, Atmospheric electrical field measurements near a fresh water reservoir and the formation of the lake breeze, Tellus A 68 (2016) 31592.

[42] R.G. Harrison, K.S. Carslaw, Ion-aerosol-cloud processes in the lower atmosphere, Rev. Geophys. 41 (3) (2003) 1012. 